\title{
Conf? $750850-1$
}

THERMAL CONDUCTIVITY OF IRRAD!ATED, AODITIVELY-COLORED AHD DEFORMED MGO*

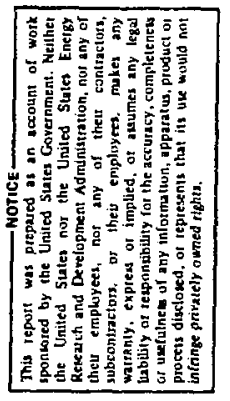

Judith B. Hartmann, Harold Weinstock,

Physics Department, 111 inois Institute of Techoology, Chicago, lllinois 60616

and

Yok Chen

Solid State Division, Oak Ridge National Laboratory Oak Ridge, Tennessee 37830

Low temperature themal conductivity measurements have been made on neutron-irradiated (1) electron-irradiated, additively-colcred (2) and deformed Mgo. Resonance scattering of phonons is observed in all these crystals at $T=15-20 \mathrm{~K}$. Correlation with optical measurements (3) indicate that this resonance is associated with anion vacancies. In addition, a resonance at $T \sim ! l$ in neutron-irradiated crystals is attributed to defect aggregates, which aro virtually absent in electron-irradiated (4) and additively-colored samp $1: \cdots$

Figure lo shows the thermal conductivity of Mgo irradiaced by 1.5 MeV electron; ro a done of $3 \times 10^{18} \mathrm{e} / \mathrm{cm}^{2}$. Although not shown in this figure, measuremants were also taken at lover temperatures. Thase is no fhonon scattering at $T \cdot, 1 \mathrm{~K}$. The resonance at $T \sim 20 \mathrm{~K}$ is much weaker than that observed in the neutron-irradiated samples, with an anion-vacancy concentration of $2 \times 10^{16} \mathrm{~cm}^{-3}$, as compared to $4 \times 10^{17} \mathrm{~cm}^{-3}$ for the lowest neutron dose. Following a uv bleach of an electron-irradiated sample at room temperature, a process which has been shown to partially convert (5) $\mathrm{F}^{+}$to $F$ centers (anion vacancies with one and two electrons respectively), the thermal conductivity is lower, indicating that the $F$ center is a stronger scatterer than the $\mathrm{F}^{+}$center.

\footnotetext{
Fesearch sponsored by the U. S. Energy Research and Development Administration.

toperated by Union Carbide Corporation under contract with the Energy Research and Development Administration.
} 
Whereas anion vacancies in neutron-irradia:s= $6-: 5: s:=\equiv-E$ prirarily in

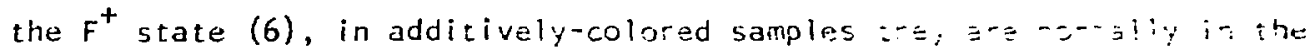

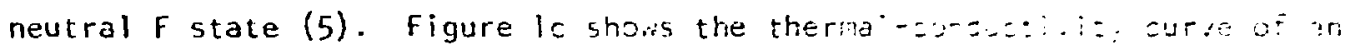

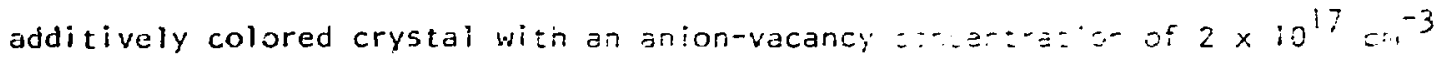

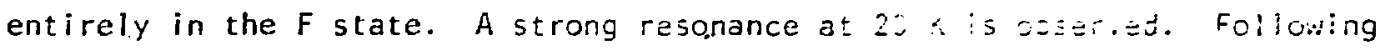
an uv bleach, which induces partial $F \rightarrow F^{+}$conversion '5). tre resonence

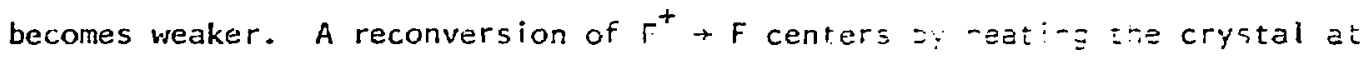
$700 \mathrm{~K}$ restores the thermal condurtivity to its or:gliej veijes. Thus, tinermal conductivity measurements on irradiated and additively-colores Mgo indicate that anion vacancies scatter phonon at $T=15-20 \%$ and the: $t 7 \equiv$ reutral $F$ center is a stronger scatterer than the $\mathrm{F}^{+}$center.

Figure Id shows the results of preliminary therpa co-duztivity measurements on a sample deformed to $-2 \%$ along a $[100]$ zirsz:ic-. Egain a dip at

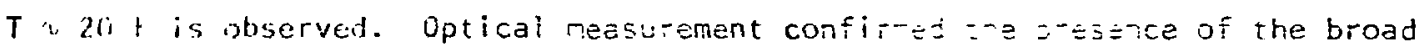

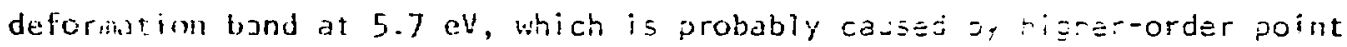

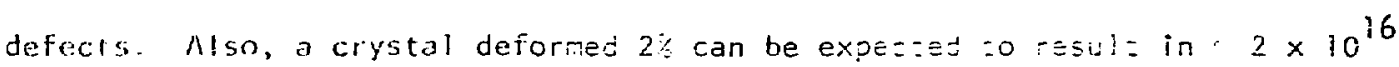
$\mathrm{F}^{+}$center/ $/ \mathrm{cm}^{3}$ (7). In addition, dislocation dipolss $z^{*}$ so gacri during deformation. Hence, at this time it is not certei- $-=i n=-i$ is the anion vacancies, other defects, or dislocation dipoles :-at are-ssz27sible for the dip in thermal conductivity. However, a subseque- rezi zeaznent at, $1000 \mathrm{k}$ partially restores the thermal conductivity to its original curve. At this temperature most of the point defects, including enion vasoncies, are annealed out, and some of the dislocation dipoles are convertej into dislocation loops (8). 
REFERENCES

1. D. S. Kupperman, G. Kurz and H. Weinstock. J. Low Tamp. Ghys, 10, 193 $(1973)$.

2. D. S. Kupperman, H. Weinstock and Y. Chan, J. Lom Tema. Pir, i. 14, 277 $(1974)$

3. Y. Chen, R. T. Williams and W. A. Sibley, Phys. Rev. 182, 960 (1969).

4. Y. Chen et al., J. Phys. C 3, 2501 (1970).

5. Y. Chen, J. L. Kolopus and W. A. Sibley, Phys. Rev. 186, 855 (1969).

6. B. Henderson and R. D. King, Phil. Mag. 13, 1149 (1965).

7. W. A. Sibley, J. L. Kolopus and W. C. Mallard, Phys. Stat. Sol. 31 , 223 (1969).

8. J. Narayan and J. Washburn, Phil. Mag. 26, 1179 (1972). 


\section{FIGURE CAPTIONS}

Iis. 1. Thermal conductivity vs. temerature for vgo rich has been (a) neutron irradiated $(Z>1$ : $(\mathrm{eV}),(0)$ electrou irmadiated $(E=1.5 \because \mathrm{eV}),(\mathrm{c})$ additively colored, eno (c) ceformed $\sim 20$ along a $[100]$ direction. 


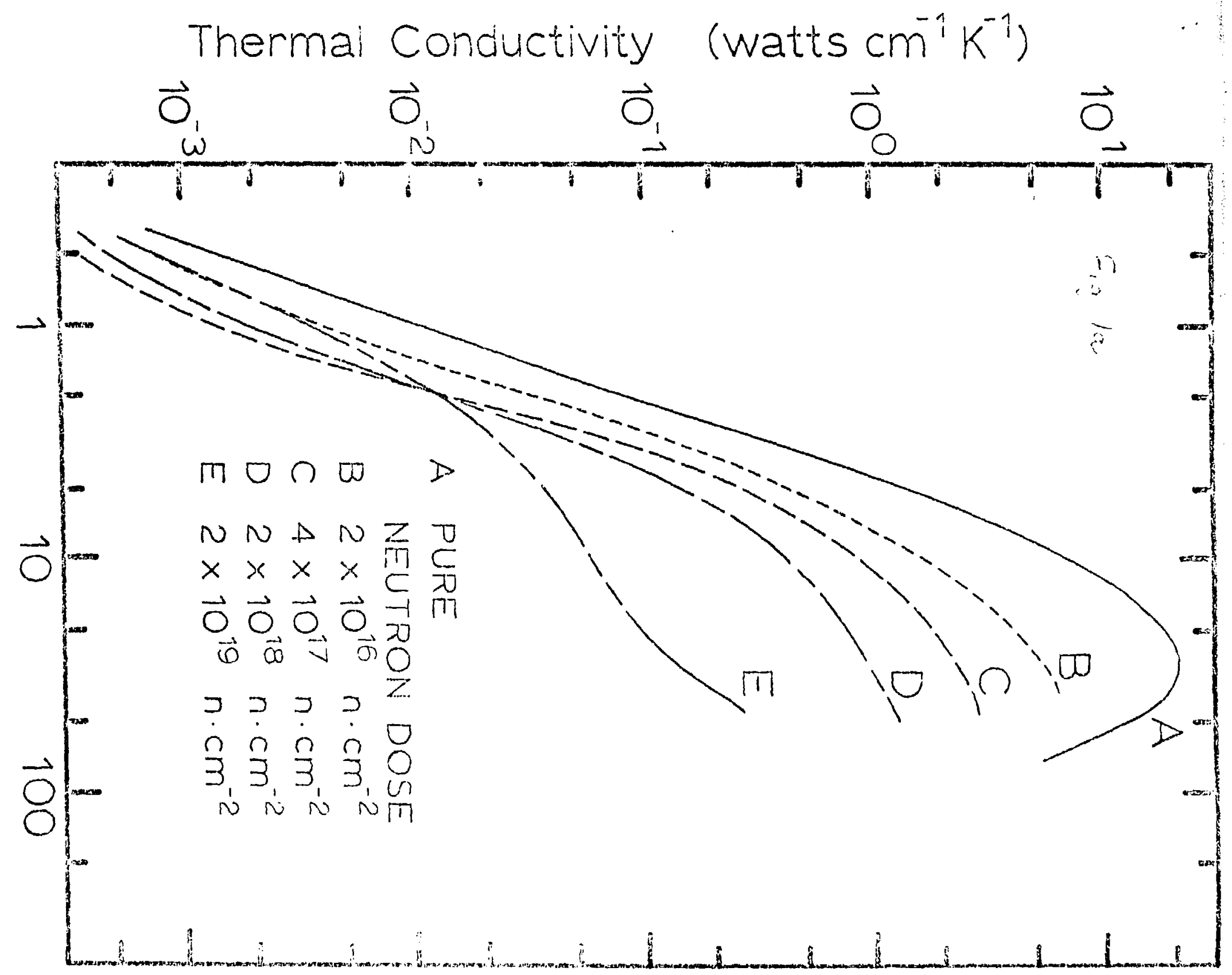




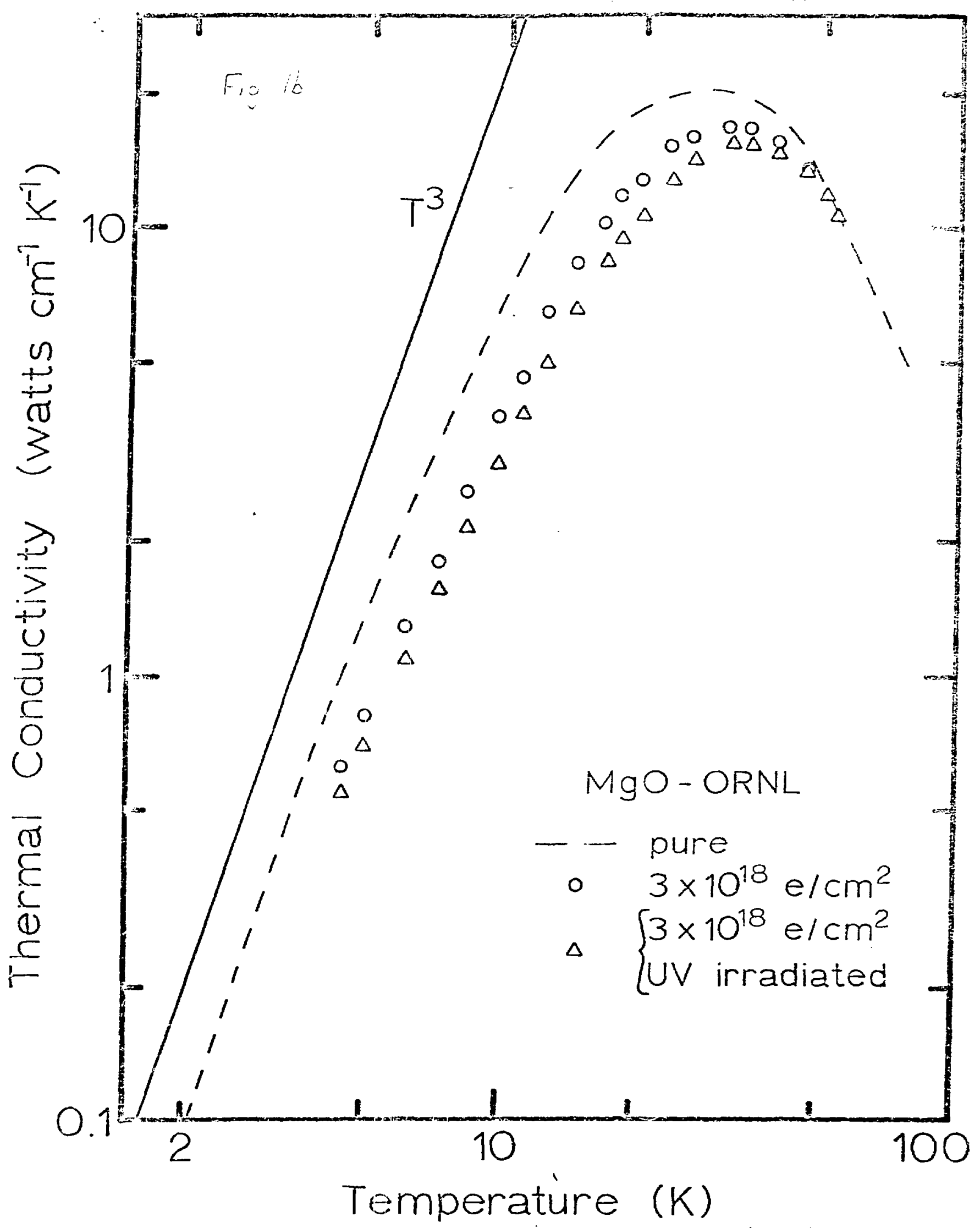




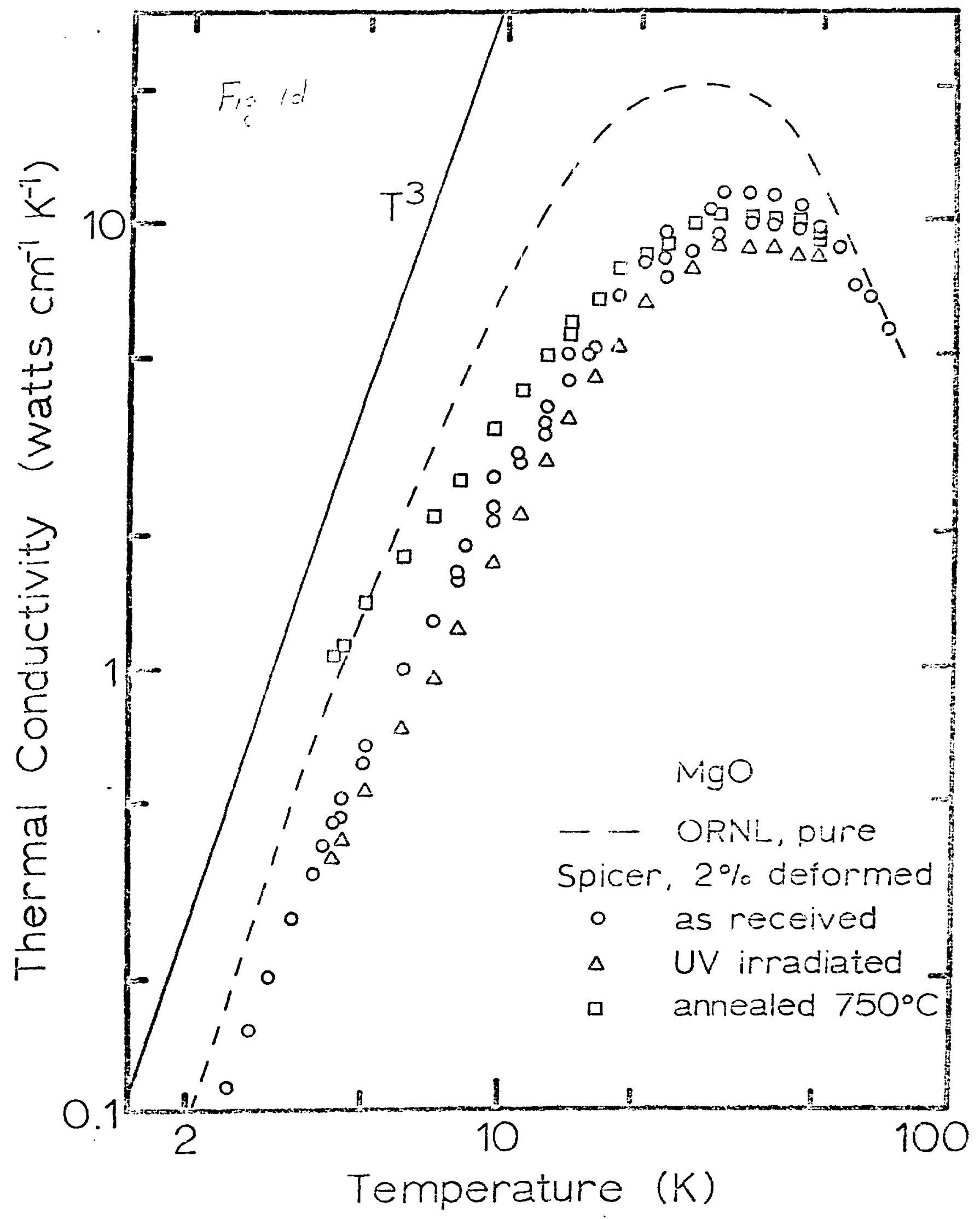

